\title{
TARSORRHAPHIA MEDIALIS VERA
}

\author{
BY
}

\author{
N. I. Shimkin, M.D., Ph.D.
}

HAIFA, PALESTINE

A NEW method of surgical treatment of long standing cases of ectropion paralyticum in lower eyelids is described below.

The author has applied this method of operation in a patient suffering from nerve leprosy. Ectropion paralyticum in the lower lid of the right eye developed in this patient about 17 years ago, and that of the left eye, about 19 years ago.

Groenouw $^{4}$ has pointed out that in this form of leprosy lagophthalmos paralyticus is observed in more than half the number of all cases, and appears during the first years of the disease; as nerve leprosy, like the present case, continues for years, lagophthalmos paralyticus gradually changes into severe forms of ectropion paralyticum, the consequence of which is keratitis e lagophthalmo, gradually leading to blindness owing to ulceration and drying up of the cornea.

Figures representing such leprous patients with different degrees of ectropion paralyticum may be found in the works of Groenouw (p. 1005), Manson ${ }^{7}$ (p. 564), Elliot ${ }^{2}$ (p. 300), Willy ${ }^{9}$ (p. 568, Vol. II) and others. With respect to its severity, the present case resembles that of Groenouw.

At present, there are few lepers in Palestine, therefore occasions for treating a long-standing ectropion paralyticum leprosum are very rare. One of these cases was operated upon by me. Dr. Canaan $^{1}$, for many years director of Lepra Hospital in Jerusalem, pointed out in an article in 1927, that there were in Palestine about 80 patients with leprosy in different stages. In a private letter, dated November 22, 1936, he kindly informed me that in Palestine and Trans-Jordan, there were about 80-100 lepers; " The nodular and mixed forms are prevalent over the nervous form."'

But, according to Rogers $^{8}$, in all the world there are from 2-3 million lepers, several hundred thousand of whom, probably, suffer, from consequences of lagophthalmos and ectropion paralyticum. Groenouw, Elliot and King indicate that in such cases the operation, tarsorrhaphia medialis, should be applied, the more so that "lepers tolerate operation upon the eyes very well," (King) ${ }^{5}$.

However, long-standing ectropion paralyticum of the lower lids is met with not only in lepers. Paralysis facialis superior, due to quite different causes, may, in some cases lead to severe forms of long standing ectropion paralyticum of the lower lids, if a timely operation is not performed. 
Loehlein ${ }^{6}$, who had collected all the methods for surgical treatment of ectropion paralyticum of the lower lids by means of tarsorrhaphia medialis, points out, justly, that all these methods are applicable only in slight cases of lagophthalmos paralyticus, and that all the methods of tarsorrhaphia medialis offered, are actually only blepharorrhaphia medialis, as with all these methods, the tarsus of the lids is not included in the operation at all, and only a strip of skin round the inner canthus of the upper and lower lids of the eye is excised, then the skin edges are sutured together. In this way, the inner part of the paralysed lower lid is lifted and comes into closer contact with the eyeball, and, principally, the puncta and canaliculi of the lower lid are kept in position.

Fuchs ${ }^{3}$ points out that in long-standing cases of ectropion paralyticum not only is the lower lid not kept in contact with the globe, but is everted outside in the inner canthus too; besides, it is elongated owing to its having stretched downwards.

In those long-standing cases, Fuchs simultaneously applies two operations upon the same lower lid; in the inner canthus, he performs blepharorrhaphia according to Arlt; and in order to shorten the lid, he excises a triangle on the outer third; then he sutures the sides of the triangle together.

The purpose of this double operation is to shorten the lower lid and keep the lacrymal passages intact.

But in long standing ectropion paralyticum as in our case, the punctum lacrimale is occluded to such an extent, that it is difficult to trace it even with a loupe; and even a thinnest conical probe cannot be inserted into the canaliculus lacrimalis. No restoration of lacrymal ducts can be thought of in these cases at all.

In those cases of ectropion paralyticum, where the lacrymal passages of the lower lid cannot be restored, the surgeon has only one aim, i.e., to give the lower lid its normal position, in order to keep the cornea from drying up and ulcerating by covering it with the lid. Retention of tears in the conjunctival sac, resulting from the difficulty of their flowing away, in the above cases of ectropion, is rather a beneficial factor. The constantly wet cornea becomes more transparent and the vision improves.

In the case described below, I have noticed that, thanks to continuous moistening of the cornea by tears, the vision improved, the right eye beginning to distinguish the number of fingers at a distance of 4 metres, as against 1 metre before the operation; and the left eye, at that of $2 \frac{1}{2}$ metres as against $\frac{1}{2}$ metre.

I beg to offer my method of operation, the tarsorrhaphia medialis vera, only for such long-standing cases of ectropion paralyticum.

This method differs from the tarsorrhaphia used up till now in that by its means the severest ectropion paralyticum medialis may 
be corrected without any additional operation on the outer third of the lid as in the method of Fuchs.

This method is a true tarsorrhaphia, as in it, the tarsi of both lids in the inner part are sutured, and not the skin only as in the method of tarsorrhaphia suggested up till now. In this method, it is possible to lift the lower lid as high as the surgeon considers desirable.

The close fitting of the lid to the globe is well attained. Finally, the tarsi sutured together, provide a denser support to the lower lid and protect the eye more securely from a possible relapse of lagophthalmos. Besides this, the lacrymal passages of the upper lid remain intact.

The substance of the operation consists in the following: the conjunctiva having been freshened, the medial ectropionised part of the lower lid, freed from the skin, is drawn by means of two looplike sutures inside a deep pocket, made by splitting the medial part of the upper lid into two plates.

The depth of the pocket in the inner part of the lid and the degree of drawing in of the lower lid inside it, are regulated by the surgeon during the operation.

Before describing all the steps of this simple operation in detail, I beg to cite the history of the disease in my case.

History.-October 25, 1936. The patient A.K., is 50 years old, a farmer(fellah). He does not remember the beginning of the disease. Red spots appeared on the forearm and on the wrists of both hands before the War (25-30 years ago). Soon similar spots appeared on shins and the soles of both feet. Then wounds began to appear on fingers and toes. The patient does not remember precisely, how long the wounds on hands and feet have continued, but only points out that first the fingers began to fall painlessly off, and then the toes. On the back of the left sole there is still a deep wound which has not been healing for 2 years.

The epiphora of the left eye began about 19 years ago, that of the right, 17 years ago. Soon the lower lids of both eyes began to roll out, first that of the left eye, and then of the right. At first there were many tears, and then the quantity of tears went on diminishing ; the eye began " to dry up and darken." The vision has been decreasing. He distinguishes the road with difficulty. The patient came to the clinics with a request to keep his vision. He has been married 15 years. His wife is 30 years old, his son is 8. All the family are well.

State.-October 25, 1936. The patient is of medium height, has á very weak constitution. He represents a typical picture of nerve leprosy which in the present case differs in nothing from the typical cases described in the manuals mentioned above. As to the change in the region of the eye a complete degenerative atrophy of 
all mimic muscles, draws our attention, together with an inveterate bilateral peripheral affection of the upper nervi faciales. Only the musculus supercilii dextri, as it is seen in the figure (photo 1) may be still voluntarily lifted up in its outer part, thanks to which the outer part of the right eyebrow is somewhat raised upwards. The I and II branches of the fifth nerve are also affected, owing to which a decreased thermal, tactile and pain sensibility of the skin, the face and also of conjunctiva and cornea, and a retarded winking are observed. On the part of the oculomotor nerve only a complete paralysis of the sphincter pupillae is observed, owing to which the pupils are greatly dilated and absolutely immobile. The upper lids, owing to the atrophy of the orbicularis palpebrarum, hang mechanically down, due to their weight, giving a picture of hemiptosis.

The lower lids are not in contact with the eyeball, and in their inner part hang down and are rolled out to such an extent that the puncta lacrimalia are lying as if on the cheek; the conjunctiva near them has a skin-like appearance. The puncta lacrimalia and canaliculi lacrimales are so occluded that it is impossible to insert into them the finest conical probe even with the help of a loupe. When the upper lids are lowered, the cornea in the lower third remains uncovered. The distance between the puncta of the upper lowered and lower lid in the right eye is $9 \mathrm{~mm}$., and in the left eye $11 \mathrm{~mm}$. The conjunctiva bulbi in the region not covered by the lower lid is dry and has a skin-like appearance. The cornea in the lower and middle thirds has grown opaque to such a degree that the pupil and iris are indistinctly seen. The upper third of the cornea is very slightly opaque and it is possible to see only the dilated and absolutely immobile pupil. There are no inflammatory processes in the anterior part of the eyeball. Owing to the opacification of the cornea no ophthalmoscopy is possible. All the movements of the eyeball are normal. Vision : R.E. = counting fingers at one metre distance. Vision : L.E. = counting fingers at a distance of $\frac{1}{2}$ metre. Tension-normal.

We will dispense with the analysis of separate symptoms of the above history of the disease, in order not to go beyond the boundaries of the title of the article; it should be only pointed out that in the present case there was a long-standing ectropion paralyticum leprosum which had reached its extremest degrees in the inner part of the lower lids of both eyes, which was aggravated by a total occlusion of puncta lacrimalia and canaliculi lacrimales. In consequence of a long-standing ectropion, drying up and opacification of the cornea had appeared, which led to a great decrease of the vision. The retarded winking and a diminution of the sensibility of the cornea and conjunctiva could cause a further opacification of the cornea and bring about a total blindness. Thus there were 
present all the indications for an operation to correct the ectropion paralyticum of the lower lid.

When choosing the method of operation, it was necessary to take into consideration the presence in this case of the atrophy of the lids, muscles and tarsi, occurring in lepers (Groenouw), and besides, the degree of ectropion and principally the impossibility of restoring the lacrymal passages of the lower lid. All the operations blepharorrhaphia medialis, mentioned above, are applicable in slight cases of lagophthalmos; and in the present case could not give the required improvement of such a severe ectropion. The Arlt-Fuchs operation wounds the lid at its inner and outer thirds and atrophy of the tarsi and lids being present, this operation could not achieve a satisfactory result. Therefore, it was necessary to select an operative method which would effect the highest raising and shortening of the lower lid; its close contact to the globe, and the least trauma of the tissues of the lid.

The method of operation c'escribed below, tarsorrhaphia medialis vera, gives a complete correction of a long-standing ectropion, with the least trauma of the lid.

\section{Description of the Operation}

Instruments.-Fixation forceps, half-bent scissors, keratome, Jaeger's spatula, a sharp scalpel, needle-holder. 3 threads armed with needles at both ends, and 1 thread with 1 needle.

Preparation for the operation. - The skin of the lid and the inner part of the eye are washed well with soap and smeared over with iodine.

Anaesthesia. -2 c.c. sol. novocaine 2 per cent. + adrenalin are injected subcutaneously in the inner part of the lower and upper lids. 2 to 3 drops of sol. pantocaine 1 per cent., or sol. cocaine hydrochlor. 3 per cent. are instilled into the conjunctival sac.

\section{The Operation.-}

\section{1st Step}

(Fig. I. A). Cutting off with scissors of the skin of the inner part of the lower lid from the beginning of the ligament down to the lower punctum lacrimale and $2 \mathrm{~mm}$. outward from it. The width of the skin cut off from the actual edge of the lid downwards is $1 \frac{1}{2} \mathrm{~cm}$.

(B) Scarification of the margin of the lower lid and the conjunctiva near it along all its width up to the eyeball; the scarification begins from the inner canthus of the eye, including caruncula lacrimalis and plica semilunaris, down to the punctum lacrimale and $2 \mathrm{~mm}$. outward from it. 
(C) Splitting of the upper lid, along the intermarginal line into two plates, by means of the keratome, beginning from the punctum lacrimale superior to the inner canthus of the eye. When splitting, the punctum and canaliculus of the upper lid are kept intact. (For convenience of splitting the Jaeger hornplate may be laid under the border of the upper lid.)

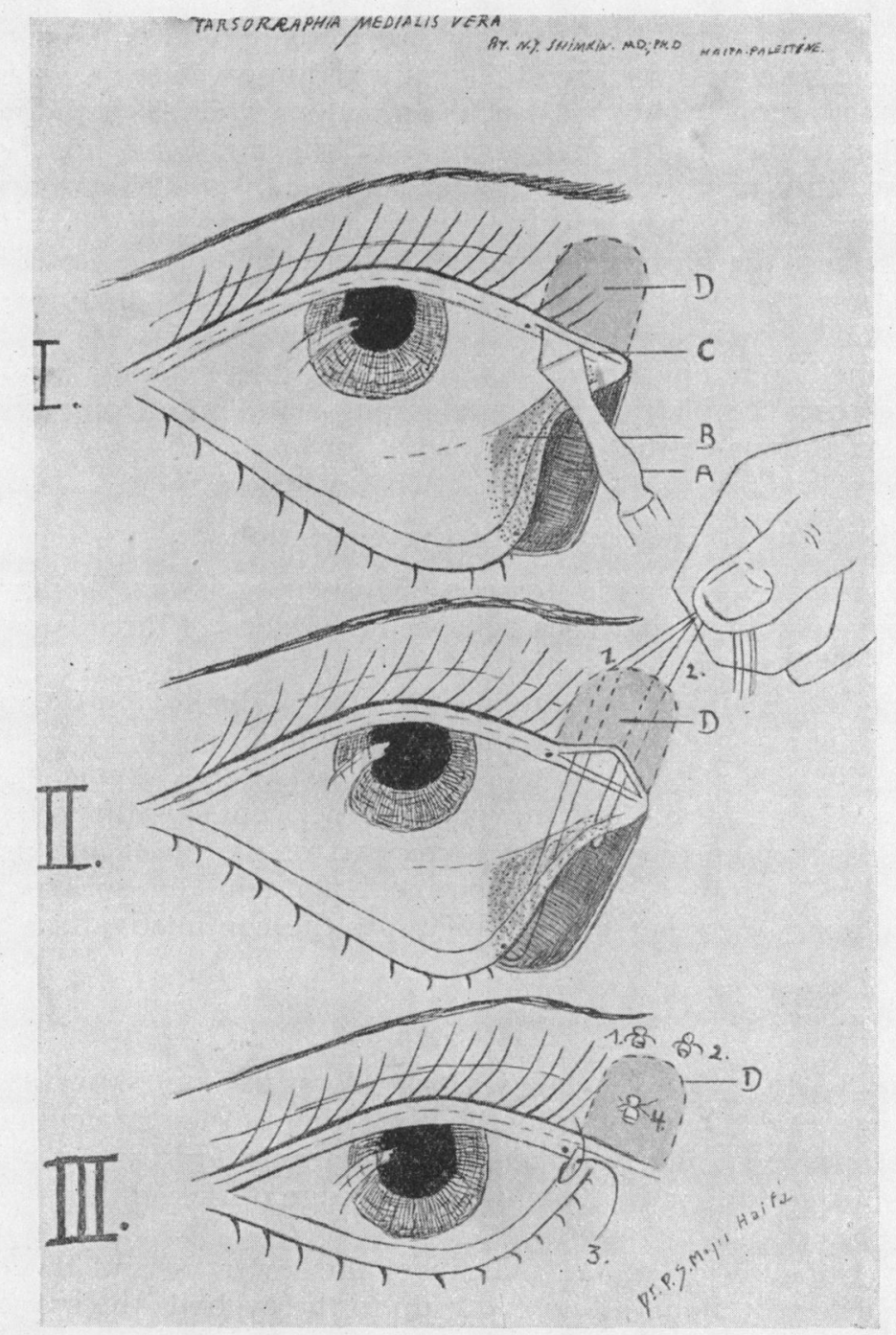

FIGs. I, II, III. 
(D) The slit produced is enlarged to $1 \frac{1}{2} \mathrm{~cm}$. in height and width by means of the keratome or scalpel, thanks to which a deep pocket is produced in the inner part of the upper lid.

\section{2nd Step}

Table (Fig. II). Application of sutures. The needle of the first suture is introduced into the inner part of the lower lid 1 to $1 \frac{1}{2} \mathrm{~mm}$. externally from the punctum and $1 \mathrm{~mm}$. lower than the lid border; next to the first suture, $2 \mathrm{~mm}$. medially, the second needle of the same suture is put through. The needles pierce the whole thickness of the lid from the outside in wards. The threads led out are introduced in the hollow of the pocket in the same order and piercing its top, go out over it. The distance between the threads carried outside is $2 \mathrm{~mm}$. (Fig. II, 1).

The second suture (Fig. II, 2) is inserted in the same order in the lower lid, $3 \mathrm{~mm}$. medially from the first suture; and both threads of the second suture are also introduced inside the pocket and go out over its top, $3 \mathrm{~mm}$. medially from the first suture (Fig. II, 2). The threads having been brought out, all four are taken hold of by the thumb and forefinger and are drawn upwards. The inner ectropionised end of the lower lid is drawn into the hollow of the pocket, while the upper wall of the pocket is being raised upwards with forceps, thus enlarging the entry into it.

The surgeon uses his discretion whether to draw the threads tighter in order to raise the lower lid higher, or to slacken the threads, if the lid is shortened too much, and its contact with the eyeball is therefore too close. The surgeon being satisfied that the position of the lid is correct, the sutures are tied over a cotton-wool or gauze tampon (Fig. III, 1, 2). The result of the operation is seen immediately on tying the first and second sutures.

\section{3rd Step}

The newly formed inner canthus consists of 3 layers : 2 layers of the split upper lid and a layer of the tarsus and tissue of the inner part of the lower lid, drawn in between the first two. All the 3 layers are fixed together by means of a single suture in the following way :-

The needle pierces in the canthus all the three layers from inside out. This suture is tied over a gauze or cotton-wool tampon with a surgical knot. (Fig. III, 3.) In the figure the threads are free, the knot is not tied. Then to compress all the 3 layers to each other, a single loop suture is applied to the middle of the former pocket, in such a way that each needle of this suture is introduced under the newly formed inner canthus from inside out at a distance 
of $2 \mathrm{~mm}$. from each other. The threads of this suture are tightly tied over a gauze or cotton-wool tampon. (Fig. III, 4.)

The operation being over, 5 per cent. xeroform ointment and a pressure bandage are laid on both eyes.

Post Operation Period.-The first bandage is changed in 2 days. On the fifth day the sutures are taken out and a bandage is put only on the operated eye for two days more. After 7 days the patient

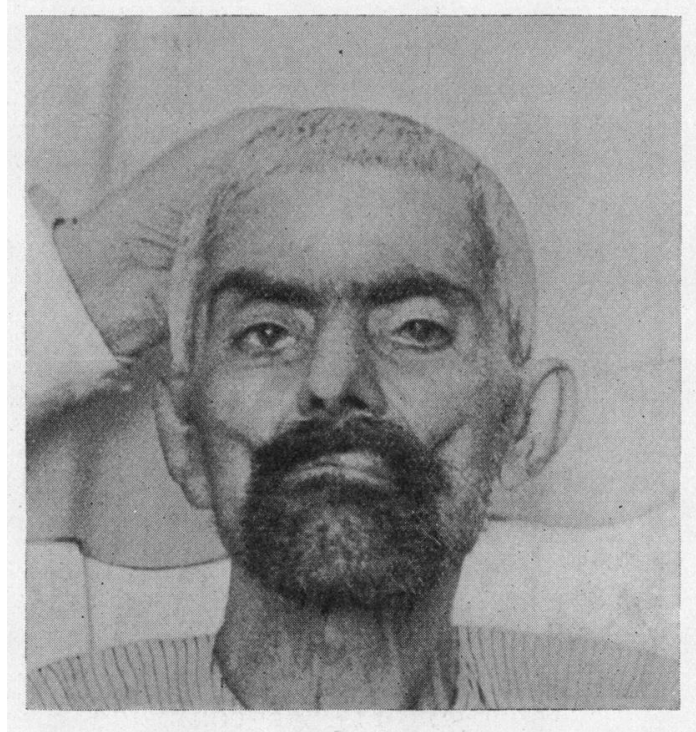

Рното 1.

is sent home. The result of the operation is seen both in Fig. III and in photo No. 1.

On the 8th day after the operation, i.e., on November 2, 1936, the patient was demonstrated by me in the Society of Jewish Physicians in Haifa. On the next day after my report, Dr. Izkovich, the President of the Society and Director of the Roentgen Institute, kindly photographed the patient. (Photo 1.)

In the photo annexed, it is possible to see the close contact between the lower lids and the eyeball and a quite satisfactory cosmetic effect. The closing of the eyelids is nearly complete, in spite of the atrophy of the orbicularis of the upper lids usual in patients affected with nerve leprosy; such atrophy impeding the tight closing of the lids.

The therapeutic result of the operation was that the cornea of both eyes and the conjunctiva of the lower part of the eyeball were 
copiously moistened with tears retained by the lower lid. It may be seen in the photo how the tears have gathered in the inner canthus of the right eye. The patient has noticed the disappearance of the feeling of dryness and burning in the eye and an improvement of vision too. The vision of the right eye on the 8th day after the operation was equal to counting fingers at a 4 metre distance ( 1 metre before the operation); that of the left eye $2 \frac{1}{2}$ metres (before the operation $\frac{1}{2}$ metre). For the uncomplicated needs of a farmer (fellah) such vision is sufficient: it gives the patient the ability to move independently, without anybody's help.

The simplicity of the operation and attainment of a good covering for the cornea by means of raising and shortening the lower lid in the inner part of the eye, induced me to offer to the attention of ophthalmologists this new method, tarsorrhaphia medialis vera, in such long-standing cases of ectropion paralyticum where the lacrimal passages of the lower lid are so occluded that their physiological functions cannot be restored.

\section{Summary}

The author offers a new method of operation, tarsorrhaphia medialis vera for cases of ectropion paralyticum of the lower lid where the punctum and canaliculus lacrimalis are so occluded that the physiological function of the lower lacrymal passage cannot be restored.

The operation consists in drawing the inner part of the lower lid, from the punctum lacrimale up to the inner canthus, by means of two loop sutures upwards and inside a deep pocket, made in the inner part of the upper lid; the pocket is made by means of splitting the margin of the upper lid along the inter-marginal line into two plates, beginning from the punctum superior and up to ligamentum internum. The punctum and canaliculus of the upper lid remain intact in this operation.

On the medial part of the lower lid the skin is previously excised, and the conjunctiva and lid margin are scarified, which causes its adhesion, when healing, to the tissues of the upper lid pocket walls. All the three layers are fastened together with a single knot suture in the newly formed canthus of the eye, and with a loop stitch inwards frum it. (Fig. III, 3, 4.)

The operation is called tarsorrhaphia medialis vera, as according to its method the tarsi of both lids are sutured in the inner eye canthus, and not only the skin of the lids, as occurs in all the methods of tarsorrhaphia medialis, devised up till now. This operation gives the surgeon the possibility of gauging the amount to raise and shorten the lower lid according to what is necessary. The cosmetic result is quite satisfactory. 


\section{REFERENCES}

1. Canaan, T.-Die Lepra in Palaestina. Archiv fur Schiff- und Tropenhygiene, S. 21, H. 1, Bd. XXXI, 1927.

2. Elliot, R. H.-Ophthalmologie Tropicale. Traduction Francaise, 1922.

3. Fuchs, E-Lehrb. d. Augenheilk., S. 997, XIII Aufl., 1921.

4. Groenouw, A.-Beziehungen der Allgemeinleiden und Organerkrankungen zu Veranderungen und Krankheiten des Sehorgans. Abteilung 1. Graefe-Saemisch Handb. d. Augenheilk., III Aufl., 1920.

5. King, E.-The Eye in Leprosy. Brit.Jl. of Ophthal., Oct., 1936, p. 568.

6. Loehlein, W.-Operationen an den Augenlidern. Graefe-Saemisch Handb. d. Augenheilk. Augenaerztliche Operationslehre I, S. 162. Zweite und dritte Auflage, 1922.

7. Manson, S.-Tropical Diseases. X Edition, 1935.

8. Rogers, L.-Leprosy. Encyclopaedia Britannica, Vol. XIII, p. 957, 1929.

9. Willy, Alexander.-Spezielle Pathologie und Therapie innerer Krankheiten, herausgegeben von Friedrich Kraus und Theodor Brugsch. X Bd., 1 Teil.

\section{THE WATER-BINDING OF THE BRAIN}

BY

J. A. VAN HEUVEN and P. F. FischeR

UTRECHT

IN our last paper on "The Water-Binding of the Optic Nerve and of its Sheaths," we came to the conclusion that the optic nerve is capable of taking and keeping such quantities of water that this capability may play some part in the origin of a papilloedema. As the result of their pathologico-anatomical investigations in this field, Spatz and Marchesani came to the conclusion that papilloedema can be compared with the "Zysternenverquellung " which was seen by Spatz in the brains of patients suffering from brain tumour. If this conclusion is accurate it follows necessarily that the water-binding power of the brain tissue must be similar to that of optic nerve. Now it is a matter of common knowledge that brain tissue absorbs water, and the expression " oedema of the brain" is commonly used. In both this question, however, and in the use of the term " papilloedema" cne is inclined to think solely of the histological picture and not to consider the physico-chemical conditions.

Some investigations were made formerly by M. H. Fischer and his collaborators in the absorption of water by nervous tissues and brain tissues of rabbits. These authors worked with complete sets of brains, and their investigations were limited to a small number of experiments. They arrived at the important conclusion that brain tissues are quite capable of absorbing water, especially in weak acid solutions, and furthermore that an increase of weight of only 10 per cent. of brain tissue was sufficient to 